\title{
Sociocultural theory and reading comprehension: The scaffolding of readers in an EFL context
}

Ghafar Samar, Reza

Tarbiat Modares University, Tehran, Iran (rgsamar@gmail.com)

Dehqan, Mahmood $\square$

Allameh Tabataba'i University, Iran (dehghanm361@yahoo.com)

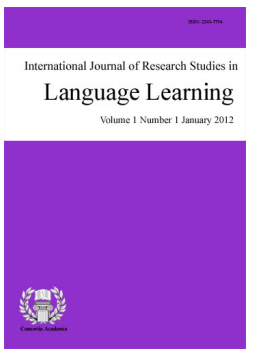

ISSN: 2243-7754 Online ISSN: 2243-7762

OPEN ACCESS

\section{Abstract}

The focus of the present study was to investigate the possible effects of sociocultural-based teaching techniques on EFL learners reading comprehension. The basic purpose was to clarify how learners reading comprehension and strategy use could be affected by the types of teaching techniques and how high and low proficiency learners profited from the intervention. Iranian EFL students were used as the participants of the study. A NELSON language proficiency test, a researcher-made reading comprehension test and a reading strategy questionnaire (adopted from Phakiti, 2006) were used as data collection instruments. The results showed that the sociocultural teaching techniques leads to better reading comprehension and reading strategy use for EFL learners. Also shown that proficiency factor played a determining role in reading comprehension development of the two groups of this study and that the low proficiency learners, especially in sociocultural group, outperformed the high proficiency learners. However, the interaction effect between proficiency factor and teaching method was non-significant for reading strategy use; leading to the conclusion that strategy use of the learners was not affected by their proficiency level. This indicates that the patterns of cognitive and metacognitive strategy scores are similar for students of low and high proficiency.

Keywords: reading comprehension; reading strategy use; proficiency level; sociocultural theory; scaffolding 


\section{Sociocultural theory and reading comprehension: The scaffolding of readers in an EFL context}

\section{Introduction}

For many years reading has been viewed purely from cognitive perspective and a great deal of research has focused on the cognitive aspect of reading. For those who are working in this area, reading is considered as a receptive skill and the central question is what cognitive processes underlie and account for success and failure in learners' attempt to master the second/foreign language in general and second/foreign language reading in particular (King, 1987; Rueda, MacGillivray, Monzo, \& Arzubiaga, 2001; Segalowitz \& Lightbown, 1999). For cognitive theorists and researchers the main areas of inquiry include memory, information processing approaches, attention and noticing. Claros (2008) stated that:

Cognitive theorists conceived language learning as a cognitive and individual process in which knowledge is constructed as the learner 1) is exposed to comprehensible input, 2) is given opportunities to both, negotiate meaning, 3) and receive negative feedback. They tend to agree that a learner needs to be exposed to input. However, there is no agreement on the type of input needed and much less, how such input is processed in order to become acquired (p. 145).

The main criticism leveled against this view to language learning in general is that the social context of learning is overlooked to a great extent. This criticism, which is drawn upon from sociocultural theory of learning, tries to put more focus on the social factors in the process of learning. It states that learning is not an individualistic process and it needs to be learned in a social context with the help of some peers or expert teachers (Lantolf \& Thorne, 2006; Yang \& Wilson, 2006; Zuengler \& Miller, 2006). Unlike cognitive approaches which view learning as something that is to be learned based on some predetermined stages, sociocultural theory maintains that learning takes place in a sociocultural environment and views learners as active constructors of their own learning environments (Johnson, 2006; Mitchel \& Myles, 2004; Williams \& Burden, 1997). Sociocultural theory, like cognitive theory, is concerned with cognitive development but unlike cognitive theory it puts social factors first. In other words, sociocultural theory states that without social interaction with other more knowledgeable peers, cognitive development will not occur. Indeed, mediation and scaffolding are prerequisite for cognitive development to take place (Aljaafreh \& Lantolf, 1994; Lantolf \& Thorne, 2006).

The Zone of Proximal Development (ZPD) is a central concept in sociocultural theory that explicates the important role of teachers as mediators and is at the heart of the concept of scaffolding (Clark \& Graves, 2004; Huong, 2003; Kozulin, 2004; Lantolf \& Poehner, 2008; Lantolf \& Thorne, 2006). ZPD refers to:

What an individual can accomplish when working in collaboration with others versus what he or she could have accomplished without collaborations with others (Zuengler \& Miller, 2006, p. 39).

In this regard, reading which was viewed traditionally as a purely individualistic skill has been looked from a completely different perspective. From the viewpoint of sociocultural theory of learning (Lantolf, 2006; Remi \& Lawrence, 2012), reading is a social skill which requires an active participation and interaction of the learners involved in it. In this regard, this study is an attempt to show the effectiveness of using sociocultural teaching techniques on EFL learners' reading comprehension and reading strategy use.

\section{Background}

An area of inquiry which traditionally received great attention in L2 acquisition in general and L2 reading comprehension in particular is the study of the effect of teaching reading strategies on reading comprehension 
development of the EFL/ESL learners (O'Malley \& Chamot, 1990; Oxford, 1996; Purpura, 1999). Several researchers have investigated the possible effect of teaching different reading strategies on the learners development of reading skills and their findings show that reading strategy instruction help poor readers improve their reading comprehension ability (Anderson \& Roit, 1993; Block, 1993; Maghsudi \& Talebi, 2009). Nevertheless, strategy instruction to ESL/EFL learners show mixed and to some extent contradictory results. Klingner and Vaughn (1996) reported positive results with Hispanic ESL students. In their study students were encouraged to use their L1 among their peers to clarify misunderstanding even though the teacher did not speak their language, whereas Cotterall (1990) reported no significant improvement in the reading comprehension of the ESL pre-university participants after implementing reciprocal teaching intervention of reading strategies.

Block (1986, cited in Koda, 2005) in his study on native and non-native English-speaking College students found that knowing which strategies to use is minimally sufficient, because knowledge alone neither discriminates between successful and less successful readers nor predicts effective strategy use. In another study aimed at describing and understanding the metacognitive knowledge and strategic reading processes of proficient and less proficient bilingual readers, Jimenez, Garcia, and Pearson (1995) reported that proficient English and Spanish biliterate readers, like expert monolingual readers, demonstrated remarkable strategic abilities during the reading process.

With the advent of a more social perspective on language teaching and learning, Vygotsky's sociocultural theory of learning has received great attention. As it was mentioned earlier, it puts the social factors first and the individual factors second. It means that the social aspects are primary for learning to take place in the individual. In order to implement the sociocultural theory in a learning context some techniques have been proposed from which scaffolding is a widely accepted and acknowledged one. Many teachers and scholars in the field tried to utilize scaffolding techniques in their classrooms and for their research purposes. Scaffolding is described by Wertsch (1979) as a "dialogically produced interpsychological process through which learners internalize knowledge they co-construct with more capable peers" (cited in Lantolf \& Thorne, 2006, p. 282). Research on scaffolding in the L2 context has been directed toward expert-novice interaction for many years. Studies on expert-novice interaction indicate that expert mediation and scaffolding is beneficial in learning grammar and language form if provided adequately (Anton, 1999; Donato \& Adair-Hauck, 1992; Lantolf \& Aljaafreh, 1995; Schinke-Llano, 1993). Their findings also reveal that excessive support from the expert may impede language development. The approaches of these studies have been either from the qualitative perspective through micro-genetic analysis or from the quantitative perspective, involving early language learners or adolescents.

Donato (1994) extended the scaffolding framework and stated that learners can scaffold one another in the same way experts provide assistance for the learners. Donato (1994) addressed the importance of peer scaffolding to second language development in classroom learning. He examined three adult English speakers in learning the French past compound tense of reflective verbs in an oral activity. He found that students worked out the correct form through successive individual contributions in collaboration. Some of the forms worked on collaboratively were successfully re-used after the interaction. Donato proposed that learners' collaboration or mutually constructed assistance in group work and collaborative tasks has the potential to foster learning. Based on Donato's results, the peer interaction of individuals, who form mutual scaffolding, enabled them to accomplish tasks collaboratively that they might not have the ability to carry out individually.

As the above literature shows, despite the great many research studies, reading comprehension continues to be a problematic area for EFL learners (Dreyer \& Nel, 2003). Although there are abundant research concerning the effect of strategy training on learners' reading comprehension ability in L2, few studies, if any, have scrutinized the possible effect of a socioculturally based teaching techniques on the learners reading comprehension and reading strategy use. Furthermore, all the above mentioned studies put the focus on strategy instruction as a method of teaching reading skills to EFL learners and few studies have scrutinized the effectiveness of using sociocultural techniques in learners' strategic reading repertoire. In addition, when looking back at the previous research studies carried out in the sociocultural theory and its related areas, we come to 
realize that very few, if any, have been devoted to teaching reading comprehension through sociocultural theory. Most of the research studies carried out in this area is related to teaching speaking and writing skills (Aljaafreh \& Lantolf, 1994; Barnard \& Campbell, 2005; Cotheral \& Cohen, 2003; Foster \& Ohta, 2005; Gibbons, 2003; Guerrero \& Villamil, 2000; Mccafferty, 2002; Ohta, 1995). In line with the above arguments, the purpose of the present study is to clarify how text comprehension and reading strategy use can be affected by implementing sociocultural teaching techniques and what proficiency level (high or low) profit more from the instruction. To these ends, the following research questions were posed:

1. Is there any significant difference between the performance of sociocultural and control groups in reading comprehension and reading strategy use after the intervention in L2 reading?

2. Is there any significant difference between the performances of high and low proficiency groups in their performance in reading comprehension and reading strategy use after the intervention in L2 reading?

\section{Methodology}

\subsection{Participants}

126 EFL learners from two Iranian universities (Mazandaran \& IAU) took part in this study. Since some of the students did not participate in the pre or post-test, some others did not participate in the class sessions appropriately and still others changed their classes or dropped the course, the final pool of participants consisted of 95 male / female students with the age range of 18-30. We used intact groups, actual university classes, which then formed two groups of participants, control and experimental, in which both high and low levels of proficiency learners were included.

\subsection{Instruments}

Three instruments were used to collect the data of the present study: a) NELSON language proficiency test; b) reading comprehension test and c) reading strategy questionnaire.

\subsubsection{Language Proficiency Test}

In order to homogenize and determine the level of proficiency of the two groups participating in the study, a version of NELSON Test of Language Proficiency (400 B) was administered to all learners. It consists of four parts: close passage, grammatical structures, vocabulary and pronunciation. All parts were in the form of multiple choice questions. There were in all 50 items and the time allotted was 50 minutes. The test was pilot-tested on a similar group of ten students and the reliability of the test scores according to the KR.21 formula turned out to be 75.78 which were suitable for this study.

\subsubsection{Reading Comprehension Test}

As this study aimed at investigating the effect of a sociocultural-based model of teaching on students' reading achievements, a test of reading was also used. This test was administered to learners at the beginning of the course (pre-test) to determine their reading comprehension ability. The same test was given to learners at the end of the course (which lasted10 sessions) to determine their improvement after the intervention.

In developing the test of reading comprehension, five passages were selected from the reading section of books two and three of New Interchange series (Richards, 1997). The number of words in the selected five passages ranged from 257 to 295 words. Six items were developed for each passage and in all there were thirty items for all five passages. Each item carried one point. The nature of the items in terms of recognizing main ideas, vocabulary knowledge, and inferring was the same for all passages. These texts were selected for the 
Sociocultural theory and reading comprehension: The scaffolding of readers in an EFL context

following reasons: Having a general content, being of great interest to students, being nearly of the same length and being nearly of the same difficulty in terms of structure and unknown words

The reliability of the test was also taken care of at the piloting stage through the K-R21 formula which turned out to be 0.81 . To determine the concurrent validity of the test, the correlation coefficient between the Nelson test of proficiency and the reading test in the piloting stage was calculated and turned out to be 0.79 which was suitable for the purpose of this study.

\subsubsection{Reading Strategy Questionnaire}

In order to determine the students reading comprehension strategy use, a reading strategy questionnaire (adopted from Phakiti, 2006) was used. The questionnaire consisted of 30 items and used a five-point Likert scale (Never/Sometimes/Often/ usually/ and Always) to measure the reading strategy awareness and use of the learners (Appendix A). As the participants of this study were non-English majoring students, the original questionnaire which was in English was rendered into Persian by the researchers. The translated form of the questionnaire was validated by two university instructors. The questionnaire tests cognitive and metacognitive reading strategies of learners. Cognitive strategy factors were composed of comprehending strategies, memory strategies and retrieval strategies. The metacognitive strategy factors consisted of planning strategies, monitoring strategies and evaluating strategies. This instrument offered an immediate retrospective picture of the reading behavior. In order to make sure of the internal consistency reliability coefficient of the instrument at the piloting stage it was given to 10 students of the similar proficiency level taking part in the study. Based on the data gathered, the reliability coefficient alpha was calculated to be 0.78 which seemed promising for the purpose of this study.

\subsection{Procedures}

First of all, NELSON Test of language proficiency was given to all learners to find out their proficiency level. To determine the learners' current reading comprehension ability, reading comprehension test was administered as pretest, which was followed immediately by the reading strategy questionnaire as a measure of their awareness of reading strategies. After the pretest, experimental and control groups received sociocultural and traditional reading instructions, respectively. It is also worth mentioning that both control and experimental groups were taught the same material by the same teacher. The textbook used for this study was 'Reading academically: a task-oriented approach' (Yaqubi \& Rayati Damavandi, 2009). The book was designed to develop basic reading skills of the university students.

All the students were expected to do the reading tasks from the required textbook and each session they were asked to do 2 to 4 tasks as part of the course syllabus for a total of about 10 sessions. Each session lasted about 80 minutes and the classes were held once a week. The experimental group received teacher as well as peer scaffolding while they were working on reading comprehension tasks. In other words, the data of the experimental group was collected while half of the learners received teacher scaffolding and the other half peer scaffolding. The learners in the teacher scaffolding group were informed that they would receive teacher scaffolding during their collaboration and the learners in the peer scaffolding group were told that they should carry out the task collaboratively with the help of each other and they would receive no help from the tutor in the process of doing the tasks. Each of the experimental groups of this research study was divided into 8 groups of three learners (except one group which consisted of four) to do the tasks collaboratively with the help of each other (peer scaffolding) and teacher (teacher scaffolding).

Rea-Dickins (2006) states that teacher scaffolding is a general term which is used to encompass all forms of assistance that teachers may provide to promote their learners' language awareness, development and achievement. In the teacher scaffolding group, at first the tutor asked the learners in each group to read the task carefully and do it collaboratively. They were asked to read the tasks together and do their best to accomplish the required task with the help of each other and tutor. While learners were busy doing the task in their groups, the 
tutor observed and participated in the process where necessary. Whenever the learners asked a question or whenever an error occurred, and if the reading process failed, the tutor began the scaffolding techniques. The scaffolding techniques used in this study followed the three mechanisms of effective help in the ZPD proposed by Aljaafreh and Lantolf (1994). Based on Vygotsky's theory, Aljaafreh and Lantolf stated that for intervention to be effective within the learners' ZPD, it should be graduated, contingent and dialogic. The help provided by the tutor for the learners of this study in the teacher scaffolding group was in the learners' appropriate level to encourage them to work at their potential level of ability. In other words, the tutor tried to give them the minimal level of assistance needed to work out the required tasks and if not useful, more help would be given. The tutor tried to give learners graduated help, from implicit to explicit, until they reached the appropriate level.

Another characteristic of teacher scaffolding mechanisms provided by the tutor was providing help only when it was needed. When the learner had problem and/or error in performing the needed task, the appropriate level of help would be given, and when there was no need for assistance, no help would be provided, consequently. In this regard, when the learners were in the other-regulation phase (dependency on others) the help was provided, and as the learners showed signs of independency and self-regulation the guidance was no longer given. In addition to the graduation and contingency of the scaffolding techniques, the dialogic nature of the help provided for learners was also of crucial importance in the sociocultural theory of learning. Indeed, the scaffolding given to the learners were in the form of dialogic interaction and negotiation which happened between tutor and learners. It is through this dialogic activity which the ZPD and development of the learners are identified. In addition, the students reading comprehension was scaffold in all the three phases of reading: pre, while and post reading.

As the main tenet of peer scaffolding is to unleash students from the teacher-fronted classroom (Wilson, 2005), no instruction was given to students in peer scaffolding group. However, as the learners of this study were unfamiliar with the instructional technique used and as they were, to a great extent, unwilling in doing the tasks collaboratively, the tutor tried to make some minor comments at the initial sessions of the course for peer scaffolding group. For this reason, students were given some information about how to scaffold each other. In addition, the instructor brought some example of exercises which could be helpful for scaffolding.

The traditional reading instruction was an instructor-centered model. In this model the instructor provided and controlled content, while the students were more passive recipients of information. In this instructional model the instructor had students read the text out loud in the class and lectured on the plot of the text. The instructor was responsible to conclude with comprehension questions concerning the text. Learners were asked to read the tasks carefully and work them out individually. No pair or group work was allowed and they were not allowed to have cooperation in the process of reading comprehension and doing the tasks. At the end of the study the participants were required to take the post-tests of reading comprehension and a questionnaire of strategy use of reading.

It is also worth mentioning that the scaffolding and traditional groups of the study were not divided into high and low learners during the course. At the end of the study, in the analysis phase two groups of high and low were identified based on the results of the NELSON. Those students whose scores were below the medium were taken as low and those whose scores were above the medium as high group. So, there were two groups of learners; one consisting of 50 and the other 45 learners, in which each group was then divided into low and high levels of proficiency (Table 1).

Table 1

Proficiency based group division

\begin{tabular}{lcccc}
\hline & \multicolumn{2}{c}{ Control group } & \multicolumn{2}{c}{ Experimental group } \\
Proficiency & High & Low & High & Low \\
\hline Number & 23 & 22 & 25 & 25 \\
\hline
\end{tabular}




\section{Results}

\subsection{Reading comprehension development in two groups}

In order to investigate how EFL learners' text comprehension can be affected by different teaching methods (sociocultural and traditional); the data collected from the two groups was analyzed using independent-sample t-test for pre and posttest. Table 2 presents the mean scores and standard deviations of the correct responses for the two groups before and after the intervention.

\section{Table 2}

Mean scores and SDs of the two groups in pre and posttests of reading comprehension

\begin{tabular}{|c|c|c|c|c|}
\hline \multirow[t]{2}{*}{ Groups } & \multicolumn{2}{|c|}{ Pretest } & \multicolumn{2}{|c|}{ Posttest } \\
\hline & Mean & $S D$ & Mean & $S D$ \\
\hline Control & 15.22 & 5.47 & 15.98 & 4.90 \\
\hline Experimental & 13.82 & 5.79 & 18.76 & 4.67 \\
\hline
\end{tabular}

An independent-sample t-test was used to compare the reading comprehension scores of leaners in control and experimental groups before intervention in reading comprehension. There was no significant difference in scores for control $(\mathrm{M}=15.22, \mathrm{SD}=5.47)$ and experimental groups $(\mathrm{M}=13.82, \mathrm{SD}=5.79)$ before reading intervention (Table 3$)$. As the $p$ value is more than $.05(.230>.05)$, this means that the two groups of this study had no meaningful difference in their reading comprehension performance before receiving instruction in reading comprehension.

\section{Table 3}

Independent-sample t-tests of the two groups in pre and posttests of reading comprehension

\begin{tabular}{lccc}
\hline & $t$ & $d f$ & $p$ \\
\hline Pretest & -1.209 & 93 & 0.230 \\
Posttest & 2.829 & 93 & 0.006 \\
\hline
\end{tabular}

To investigate the participants' reading comprehension performance after the intervention, another independent-sample t-test was run. The posttest scores were compared to see whether the difference in the mean scores of the control $(\mathrm{M}=15.98, \mathrm{SD}=4.90)$ and experimental $(\mathrm{M}=18.76, \mathrm{SD}=4.67)$ groups is meaningful or not (Table 3). The result reveals that there is a statistically significant difference between the scores obtained from the two group as the $p$ value is less than $.05(.006<.05)$. The experimental group which received peer and teacher scaffolding in their reading sessions outperformed the control group which were given traditional reading instruction. Their reading mean score increased drastically from 13.82 to 18.76 whereas the control group mean rose from 15.22 to 15.98 which is much lower than that obtained in experimental group. The mean difference and the meaningfulness of the difference show that the scaffolding mechanisms which were provided for the experimental group were much more conducive and beneficial to EFL learners' reading comprehension ability. The above findings, therefore, indicate that the scaffolding group had better reading comprehension development from pre- to posttest, compared to control group of the study.

\subsection{Language proficiency, intervention and reading comprehension}

As the researchers were interested to look at the individual and joint effect of two independent variables (teaching techniques and proficiency level) on one dependent variable (reading comprehension achievement), two-way ANOVA was used for the analysis of the data. Table 4 presents the mean scores and standard deviations of the correct responses of the two proficiency groups (high and low) for the two groups of this study in pre and posttest of reading comprehension. As the overall performance shows, the mean score change of the high group was 1.62 while that of the low group was 4.32. Considering the mean score change of the two groups (control and experimental), it is clear that the experimental group gained much more than the control group and the low 
Ghafar Samar, R. \& Dehqan, M.

proficiency learners gained more than high ones. The interesting point to notice is that the low proficiency learners in control group also outperformed the high proficiency learners although their gain was not that much high.

Table 4

Mean/SD of Pre/Posttest of reading comprehension with low/high proficiency in control/experimental groups

\begin{tabular}{|c|c|c|c|c|c|c|}
\hline \multirow{2}{*}{ Groups } & \multirow{2}{*}{ Proficiency } & \multicolumn{2}{|c|}{ Pretest } & \multicolumn{2}{|c|}{ Posttest } & \multirow[t]{2}{*}{ Change } \\
\hline & & Mean & SD & Mean & SD & \\
\hline \multirow{3}{*}{ Control } & Low & 12.27 & 4.72 & 14.82 & 4.22 & 2.55 \\
\hline & High & 18.04 & 4.64 & 17.09 & 5.33 & -0.95 \\
\hline & Total & 15.22 & 5.47 & 15.98 & 4.90 & 0.76 \\
\hline \multirow{3}{*}{ Experimental } & Low & 9.72 & 3.47 & 15.60 & 3.44 & 5.88 \\
\hline & High & 17.92 & 4.62 & 21.92 & 3.46 & 4 \\
\hline & Total & 13.82 & 5.79 & 18.76 & 4.67 & 4.94 \\
\hline \multirow{3}{*}{ Total } & Low & 10.91 & 4.25 & 15.23 & 3.80 & 4.32 \\
\hline & High & 17.98 & 4.58 & 19.60 & 5.03 & 1.62 \\
\hline & Total & 14.48 & 5.65 & 17.44 & 4.96 & 2.96 \\
\hline
\end{tabular}

To see whether the mean difference between the two proficiency groups is statistically significant and whether the proficiency level of the participants has any influence on their reading comprehension development, two-way ANOVAs were conducted. The results of the two-way ANOVA of the pretest of reading comprehension (Table 5) reveal that the interactive effect between the group factors (high and low) and the reading comprehension ability was not statistically significant $(\mathrm{F}=1.820, p=0.181)$, and was not strong enough for us to assume that there existed some difference between the performance patterns of the high group and those of the low group before any instruction were given to learners. But when considering the data of the two-way ANOVA for the posttest results (Table 5), we come to realize that there exists a meaningful interactive effect between the proficiency level of the learners and their reading comprehension development $(\mathrm{F}=5.621, p=.020)$. The influence of reading intervention on learners' reading comprehension development is different for learners with different proficiency levels. In line with this result, as is shown in table 4, the mean change of the low proficiency level learners in both control and experimental groups are much higher than the mean change in high proficiency learners. The same result is also indicated in the total mean change of the low group.

Table 5

Two-way ANOVA of control/experimental groups with high/low proficiency in general English knowledge

\begin{tabular}{clrrr}
\hline \multicolumn{1}{c}{ Parameters } & \multicolumn{1}{c}{ Source of variation } & \multicolumn{1}{c}{$d f$} & $p$ \\
\hline \multirow{3}{*}{ Pretest } & Reading & 2.209 & 1 & .141 \\
& Proficiency & 60.211 & 1 & .000 \\
\hline \multirow{3}{*}{ Posttest } & Interaction & 1.820 & 1 & .181 \\
& Reading & 10.797 & 1 & .001 \\
& Proficiency & 25.263 & 1 & .000 \\
\hline
\end{tabular}

\subsection{Reading strategy use in two groups}

The questionnaire was given score by assigning a weight to each row from 1 (never) to 5 (always) and the scores for each respondent was then calculated. To take into account the effect of two methods on readers' reading strategy use, independent-sample t-tests were conducted for both pre and posttest scores. The mean scores and standard deviations of the collected data are presented in table 6 . The t-test for pretest scores indicated there was no significant difference in scores for control $(\mathrm{M}=85.82, \mathrm{SD}=15.38)$ and experimental groups $(\mathrm{M}=89.18, \mathrm{SD}=17.15)$. Considering the data collected after the learners received the reading instruction, the learners' strategy use after instruction does show a significant change (Table 7). The mean score of the experimental group $(M=99.62, S D=13.56)$ is higher than that of the control group $(M=91.84, S D=16.54)$, and as 
Sociocultural theory and reading comprehension: The scaffolding of readers in an EFL context

the $p$ value does not exceed the $.05(.014<.05)$, we come to realize that the mean difference is significant and meaningful. It means that the mean difference of the two groups is attributable to reading instruction which shows that the experimental group of this study (teacher and peer scaffolding) used more reading strategies after they received the instruction. In this regard, the sociocultural group of this study used reading strategies more effectively and had better strategic performance compared to control group of this study.

Table 6

Mean scores and SDs of the two groups in pre and posttests of strategy questionnaire

\begin{tabular}{lcccc}
\hline Groups & Pretest & \multicolumn{2}{c}{ Posttest } & $S D$ \\
& Mean & $S D$ & Mean & 16.54 \\
Control & 85.82 & 15.38 & 91.84 & 13.56 \\
Experimental & 89.18 & 17.15 & 99.62 & \\
\hline
\end{tabular}

Table 7

Independent-sample t-tests of the two groups in pre and posttests of reading strategy use

\begin{tabular}{lccc}
\hline & $t$ & $d f$ & $p$ \\
\hline Pretest & 1.000 & 93 & 0.320 \\
Posttest & 2.515 & 93 & 0.014 \\
\hline
\end{tabular}

\subsection{Language proficiency, intervention and reading strategy use}

The mean scores and standard deviations of the pre and posttests of reading strategy use of the two proficiency levels for control and experimental groups are presented in table 8 . The total score change indicates that the low proficiency group (11.63) used more reading strategies for their reading comprehension tasks than the high group (5.12). At the same time, the low proficiency level readers in the experimental group (14.64) showed a much more increase in the use of reading strategies when compared with the low proficiency readers in the control group (8.23).

\section{Table 8}

Mean/SD of Pre/Posttest of reading strategy use with low/high proficiency in control/experimental groups

\begin{tabular}{lllcccc}
\hline \multirow{2}{*}{ Groups } & \multirow{2}{*}{ Proficiency } & \multicolumn{2}{c}{ Pretest } & \multicolumn{2}{c}{ Posttest } & \multicolumn{2}{c}{ Change } \\
& & Mean & SD & Mean & SD & \\
\hline \multirow{2}{*}{ Control } & Low & 81.77 & 16.41 & 90.00 & 18.04 & 8.23 \\
& High & 89.70 & 13.56 & 93.61 & 15.15 & 3.91 \\
& Total & 85.82 & 15.38 & 91.84 & 16.54 & 6.02 \\
\hline \multirow{3}{*}{ Experimental } & Low & 83.32 & 18.01 & 97.96 & 13.65 & 14.64 \\
& High & 95.04 & 14.30 & 101.28 & 13.55 & 6.24 \\
& Total & 89.18 & 17.15 & 99.62 & 13.56 & 10.44 \\
\hline \multirow{3}{*}{ Total } & Low & 82.60 & 17.11 & 94.23 & 16.18 & 11.63 \\
& High & 92.48 & 14.07 & 97.60 & 14.70 & 5.12 \\
& Total & 87.59 & 16.34 & 95.94 & 15.46 & 8.35 \\
\hline
\end{tabular}

To examine the data more closely and to investigate the possible influence of the proficiency level of the learners on their reading strategy use, two-way ANOVAs were conducted for pre and posttest scores (Table 9). The data of the pretest indicates that there is not a statistically meaningful interactive effect between the proficiency factor and the readers' use of reading strategies $(\mathrm{F}=0.347, p=0.558)$. The interesting point to note is that there is not still a statistically significant interaction between the learners' proficiency level and their use of reading strategies in the posttest. The interactive effect between the group factors (high and low) and the strategic reading use factors was not statistically significant $(\mathrm{F}=0.002, p=0.963)$, but was strong enough for us to assume that there exists some difference between the performance patterns of the high group and those of the low group. 
Ghafar Samar, R. \& Dehqan, M.

Table 9

Two-way ANOVA of control/experimental groups with high/low proficiency in general English knowledge

\begin{tabular}{clccc}
\hline \multicolumn{1}{c}{ Parameters } & \multicolumn{1}{c}{ Source of variation } & $F$ & $d f$ & $p$ \\
\hline \multirow{3}{*}{ Pretest } & Strategy use & 1.142 & 1 & .288 \\
& Proficiency & 9.274 & 1 & .003 \\
& Interaction & .347 & 1 & .558 \\
\hline \multirow{3}{*}{ Posttest } & Strategy use & 6.337 & 1 & .014 \\
& Proficiency & 1.245 & 1 & .267 \\
& Interaction & .002 & 1 & .963 \\
\hline
\end{tabular}

\section{Discussion}

The main objectives of this study were to examine students reading comprehension and reading strategy use across sociocultural and traditional teaching method, and to explore what proficiency learners (high \& low) profited more from the intervention. The results of the present study show a significant statistical difference in reading comprehension of the learners which means that the sociocultural teaching techniques (teacher and peer scaffolding) results in better reading comprehension for EFL learners and leads to higher strategic reading comprehension development in an EFL context. It postulates that sociocultural teaching techniques provide a better learning context for EFL learners' reading comprehension compared to those of the traditional method. These findings which are in accordance with previous studies (Barnard \& Campbell 2005; Cotheral \& Cohen, 2003; Gibbons, 2003; Foster \& Ohta, 2005; Mccafferty, 2002), also support the superiority of using social and collaborative techniques in learning contexts.

These findings led us to examine the obtained data in search of possible effects on reading comprehension that might have been caused by the differences in the participants' English proficiency. It was found that the low group's performance varied considerably from that of the high in that the interactive effect of the teaching method and proficiency factor was statistically significant for learners reading comprehension development and the total mean score change shows that the low proficiency learners gained much more than the high proficiency. Bearing in mind that the sociocultural group outperformed the control group and that the low proficiency learners gained more than the high, it seems reasonable to state that the low proficiency learners achieved more than the other proficiency group of this study. This finding suggests that sociocultural techniques can be used for learners from their early stages of learning process.

In addition, the other finding of this study is that learners who received sociocultural teaching techniques outperformed those who did not in their use of reading strategies. It reveals that the scaffolding techniques cater for language learning strategies in general and reading comprehension strategies in particular. This finding paves a new way for language teachers and researchers into how to equip EFL learners with language learning strategies. Unlike some researchers (Anderson and Roit, 1993; Block, 1993) who stressed the importance of teaching reading strategies as the only method for providing learners with language learning strategies, the findings of this study prove that using scaffolding and sociocultural techniques can also be effective and instructive for language learning strategies. Furthermore, the interactive effect of the teaching method and proficiency level of the learners was not statistically significant for learners reading strategy use which indicates that learners with different proficiency levels performed identically with regard to their strategic attainment in reading comprehension. This indicates that the patterns of cognitive and metacognitive strategy use development are similar for students of high and low proficiency.

These findings provide some insights into the reading comprehension process. The EFL learners found the sociocultural teaching techniques more conducive and facilitative for reading comprehension than the traditional method. There are some plausible reasons for the superiority of sociocultural group over control group in reading comprehension and reading strategy achievement. First, the sociocultural group had exposure to more aural input than the control group had, in the form of pear discussions, teacher feedback and group works. Second, the 
higher level of achievement may have been a consequence of the particular enthusiasm and high participation that the sociocultural students showed during the course. Finally, sociocultural group had a much greater variety of activities and opportunities in doing the tasks, which may have raised the interest of the students.

It should also be noted that low proficiency learners gained quiet more than high proficiency ones in reading comprehension, which can be attributed to following reasons. First, the low proficiency learners take advantage of the high proficiency learners while working cooperatively in the group discussions. Second, they make the most out of their discussion in the group and from the teachers' feedback. Finally, the teachers' feedback and scaffolding are much more tuned and adjusted for the low proficiency levels than the high levels.

\section{Conclusion}

Finally, since the present study focused on the reading performance of Iranian university students, the obtained result may have been influenced by the reading behavior of their L1 reading. The findings of the present study also hint the possibility that high proficiency learners may have been overlooked in the process of reading intervention. This suggests that they should be viewed not as superordinate that does not need guidance and help in the learning process. Rather, both high and low proficiency learners should be given the appropriate level of help and assistance until they reach the appropriate level.

In conclusion, the findings of this study recommend the use of more social and cooperative techniques in the context of language learning and teaching. It is more in favor of a collaborative learning environment which requires the presence of a peer or expert-peer that provides learners with opportunities to correct themselves and at the same time to learn the strategic processes needed for the learning of new and difficult skills. This allows EFL learners to be active constructors of their own learning environments. It is also worth mentioning that the dialogic interaction in the sociocultural context helps the learners to move from other-regulation to self-regulation; from the dependency on others to independency (Aljaafreh \& Lantolf, 1994). It means that this method is more facilitative and helpful for EFL learners to gain mastery and independency on their reading material.

\section{References}

Aljaafreh, A., \& Lantolf, J. P. (1994). Negative feedback as regulation and second language learning in the Zone of Proximal Development. The Modern Language Journal, 78(4), 471-83. http://dx.doi.org/10.1111/j.1540-4781.1994.tb02064.x

Anderson, V., \& Roit, M. (1993). Planning and implementing collaborative strategy instruction for delayed readers in grades 6-10. The Elementary School Journal, 94, 121-137. http://dx.doi.org/10.1086/461755

Anton, M. (1999). The discourse of a learner-centered classroom: Socio-cultural perspectives on teacher-learner instruction in the second language classroom. The Modern Language Journal, 83(3), 303-318. http://dx.doi.org/10.1111/0026-7902.00024

Barnard, R., \& Campbell, L. (2005). Sociocultural theory and the teaching of process writing: The scaffolding of learning in a university context. The TESOLANZ Journal, 13, 76-88.

Block, C. C. (1993). Strategy instruction in a literature-based program. Elementary School Journal, 94, 139-151. http://dx.doi.org/10.1086/461756

Clark, K. F., \& Graves, M. F. (2004). Scaffolding students' comprehension of text. International Reading Association, 570-580.

Claros, M. S. C. (2008). Psycho- linguistic and sociocultural approaches to language learning: A never ending debate. Colombian Applied Linguistic Journal, 10, 142-154.

Cotterall, S. (1990). Developing reading strategies through small group interaction. RELC Journal, 21(2), 55-59. http://dx.doi.org/10.1177/003368829002100205

Cotterall, S., \& Cohen, R. (2003). Scaffolding for second language writers: Producing an academic essay. ELT Journal, 52(2), 158-166. http://dx.doi.org/10.1093/elt/57.2.158 
Ghafar Samar, R. \& Dehqan, M.

Donato, R. (1994). Collective scaffolding in second language learning. In J. P. Lantolf \& G. Appel (Eds.), Vygotskian approaches to second language research (pp. 33-56). Ablex, Norwood: NJ.

Donato, R., \& Adair-Hauck. B. (1992). Discourse perspectives on formal interaction. Language Awareness, 1, 73-90. http://dx.doi.org/10.1080/09658416.1992.9959807

Dreyer, C., \& Nel, C. (2003). Teaching reading strategies and reading comprehension within a technology-enhanced learning environment. System, 31, 349-365. http://dx.doi.org/10.1016/S0346-251X(03)00047-2

Foster, P., \& Ohta, A. S. (2005). Negotiation for meaning and peer assistance in second language classrooms. Applied Linguistics, 26(3), 402-430. http://dx.doi.org/10.1093/applin/ami014

Gibbons, P. (2003). Mediating language learning: Teacher interactions with ESL students in a content-based classroom. TESOL Quarterly, 37(2) 247-273. http://dx.doi.org/10.2307/3588504

Guerrero, M. C. M. D., \& Villamil, O. S. (2000). Activating the ZPD: Mutual scaffolding in L2 peer revision. The Modern Language Journal, 84(I) 51-68. http://dx.doi.org/10.1111/0026-7902.00052

Huong, L. P. H. (2003). The mediational role of language teachers in sociocultural theory. English Teaching Forum, 14(3), 31-35.

Jimenez, R., Garcia, G., \& Pearson, P. (1995). Three children, two languages, and strategic reading: Case studies in bilingual/monolingual reading. American Educational Research Journal, 32, 67-97.

Johnson, K. E. (2006). The sociocultural turn and its challenges for second language teacher education. TESOL Quarterly, 40(1), 235-257. http://dx.doi.org/10.2307/40264518

King, T. W. (1987). Text modification in ESL reading comprehension. RELC journal, 18, 31-44. http://dx.doi.org/10.1177/003368828701800203

Klingner, J. K., \& Vaughn, S. (1998). Using collaborative strategic reading. Teaching Exceptional Children, 30(6), 32-37.

Koda, K. (2005). Insights into second language reading: A cross-linguistic approach. Cambridge: Cambridge University Press. http://dx.doi.org/10.1017/CBO9781139524841

Kozulin, A. (2004). Vygotsky's theory in the classroom: Introduction. European Journal of Psychology of Education, XIX(1), 3-7. http://dx.doi.org/10.1007/BF03173233

Lantolf, J. P. (2006). Sociocultural theory and L2: State of the art. Studies in Second Language Acquisition, 28, 67-109. http://dx.doi.org/10.1017/S0272263106060037

Lantolf, J. P., \& Aljaafreh, A. (1995). L2 learning in the zone of proximal development: a revolutionary experience. International Journal of Educational Research, 23(7), 51-64. http://dx.doi.org/10.1016/0883-0355(96)80441-1

Lantolf, J. P., \& Poehner, M. E. (2008). Introduction to sociocultural theory and the teaching of second language. In P. J. Lantolf \& M. E. Poehner (eds.), Sociocultural theory and the teaching of second language (pp. 1-30). London: Equinox.

Lantolf, J. P., \& Thorne, S. L. (2006). Sociocultural theory and the genesis of second language development. Oxford: Oxford University Press.

Maghsudi, M., \& Talebi, S. H. (2009). The impact of lingualuity on the cognitive and metacognitive reading strategies awareness and reading comprehension ability. Journal of Social Sciences, 18(2), 119-126.

Mccafferty, S. G. (2002). Gesture and creating zone of proximal development for second language learning, The Modern Language Journal, 86(ii), 192-203. http://dx.doi.org/10.1111/1540-4781.00144

Mitchell, R., \& Myles, F. (2004). Second language learning theories (2nd ed). Hodder: Arnold.

Ohta, A. S. (1995). Applying sociocultural theory to an analysis of learner discourse: Learner-learner collaborative discourse interaction in the zone of proximal development. Issues in Applied Linguistics, 6 , 93-122.

O'Malley, J. M., \& Chamot, A. (1990). Learning strategies in second language acquisition. Cambridge: Cambridge University Press. http://dx.doi.org/10.1017/CBO9781139524490

Oxford, R. L. (1996). Language learning strategies around the world: Cross-Cultural perspectives. Manoa HI: University of Hawaii Press.

Phakiti, A. (2006). Modeling cognitive and metacognitive strategies and their relationship to EFL reading test 
performance. Melbourne Papers in Language Testing, 1, 53-95.

Purpora, J. E. (1998). Investigating the effects of strategy use and second language test performance with high- and low-ability test takers: A structural equation modeling approach. Language Testing, 15(3), 333-379.

Rea-Dickins, P. (2006). Currents and eddies in the discourse of assessment: A learning focused interpretation. International Journal of Applied Linguistics, 16(2), 163-188. http://dx.doi.org/10.1111/j.1473-4192.2006.00112.x

Remi, A. V. C., \& Lawrence, W. (2012). Promoting sociolinguistic competence in the classroom zone of proximal development. Language Teaching Research, 16(1), 39-60. http://dx.doi.org/10.1177/1362168811423340

Rueda, R., MacGillivray, L., Monzo, L., \& Arzubiaga, A. (2001). Engaged reading: A multilevel approach to considering sociocultural factors within diverse learners. Center for the Improvement of Early Reading Achievement, University of Michigan, CIERA Report No. 1.012.

Schinke-Llano, L. (1993). On the value of a Vygotskian framework for SLA theory and research. Language Learning, 43, 121-129. http://dx.doi.org/10.1111/j.1467-1770.1993.tb00175.x

Segalowitz, N., \& Lightbown, P. M. (1999). Psycholinguistic approaches to SLA. Annual Review of Applied Linguistics, 19, 43-63. http://dx.doi.org/10.1017/S0267190599190032

Williams, M., \& Burden, R. L. (1997). Psychology for language teachers: A social constructivist approach. Cambridge: Cambridge University Press.

Yang, L., \& Wilson, K. (2006). Second language classroom reading: A social constructivist approach. The Reading Matrix, 6(3), 364-372.

Yaqubi, B., \& Rayati Damavandi, R. (2009). Reading academically: A task-oriented approach. Tehran: Rahnama Publication.

Zuengler, J., \& Miller, E. R. (2006). Cognitive and sociocultural perspectives: Two parallel SLA worlds? TESOL Quarterly, 40(1), 35-58. http://dx.doi.org/10.2307/40264510 


\section{Appendix A}

\section{The cognitive and metacognitive strategy questionnaire}

Directions: A number of statements which people use to describe themselves when they were taking a reading test are given below. Read each statement and indicate how you thought during the test. Choose 1 (Never), 2 (Sometimes), 3 (Often), 4 (Usually), and 5 (Always).

Your thinking $\quad \begin{array}{llllll} & 1 & 2 & 3 & 4 & 5\end{array}$

1. I made short notes or underlined main ideas during the test.

2. I translated the reading texts and tasks into Persian.

3. I used pictures or titles of the texts to help comprehend reading tasks.

4. I used my own English structure knowledge to comprehend the text.

5. I spent more time on difficult questions.

6. I tried to understand the texts and questions regardless of my vocabulary knowledge.

7. I tried to find topics and main ideas by scanning and skimming.

8. I read the texts and questions several times to better understand them.

9. I used my prior knowledge to help understand the reading test.

10. I tried to identify easy and difficult test tasks.

11. When I started to complete the test, I planned how to complete it and followed the plan.

12. I was aware of what and how I was doing in the test.

13. I checked my own performance and progress while completing the test.

14. I attempted to identify main points of the given reading text and tasks.

15. I thought through the meaning of the test tasks/questions before answering them.

16. I was aware of which strategy to use and how and when to use it.

17. I corrected mistakes immediately when found.

18. I asked myself how the test questions and the given texts related to what I already knew.

19. I determined what the test tasks/questions required me to do.

20. I was aware of the need to plan a course of action.

21. I was aware of how much the test remained to be completed.

22. I tried to understand the questions adequately before attempting to find the answers.

23. I made sure I understood what had to be done and how to do it.

24. I was aware of my ongoing reading and test taking.

25. I kept track of my own progress to complete the questions on time.

26. I used multiple thinking strategies to help answer the test questions.

27. I made sure to clarify the goal and know how to complete it.

28. I checked my accuracy as I progressed through the test.

29. I selected relevant information to help me understand the reading texts and answer the test questions.

30. I carefully checked the answers before submitting the test. 